\title{
UTILIZAÇÃO DO QFD COMO FERRAMENTA PARA SELEÇÃO DE REQUISITOS DE PROJETO DE UMA SEMEADORA À TRAÇÃO ANIMAL
}

Norberto Luiz Marques Andersson ${ }^{1}$, Ângelo Vieira dos Reis ${ }^{2}$, Sandro Silva Teixeira ${ }^{3}$, Antônio Lilles Tavares

Machado $^{4}$, Mauro Fernando Ferreira ${ }^{5}$

\section{RESUMO}

O ato de semear pode ser aplicado através da tração com animal ou mecanizada. No caso da Agricultura Familiar é muito comum o uso de bovinos ou eqüinos que irão tracionar um equipamento que seja adequado para pequenas áreas e que tenha a função de depositar em linha, as sementes no solo. Uma definição do tipo ideal de maquinário para realizar este serviço é de fundamental importância. Foram estudadas as necessidades dos agricultores familiares e, através da criação de um modelo decisório baseado na Matriz da Casa de Qualidade, obtiveram-se informações importantes no sentido de embasar o projeto de uma semeadora direcionada aos agricultores familiares que utilizam animais como meio de tração. Os resultados permitiram verificar que o emprego da metodologia de projeto proporciona um ganho apreciável de conhecimento durante a fase de projeto informacional. Dentre os requisitos de projeto obtidos como os mais importantes, três relacionam-se ao processo de produção e os demais ao projeto da máquina.

Palavras-chaves: casa da qualidade, máquinas agrícolas, agricultura familiar

\section{ABSTRACT \\ QFD USE AS A TOOL FOR PROJECT DESIGN OF AN ANIMAL DRAWN SEEDER.}

Planting can be performed by either animal or mechanized traction. In the case of Family Farming it is very common to use cattle or horses to pull equipment suitable for small areas with the function of depositing seeds in the soil. Definition of the ideal type of machinery to perform this service is of fundamental importance. The needs of farmers were studied by creating a decision-making model based on Home Quality Matrix, which yielded important information for designing of a seeder for family farmers who use animals as a means of traction. Results showed that the use of this design methodology provides a significant gain in knowledge during the informational project phase. Among the design requirements obtained as the most important, three are related to the production process and the other to machine design.

Keywords: home quality, farm machinery, family farming

\section{Recebido para publicação em 12/12/2013. Aprovado em 27/06/2014.}

1 - Engenheiro Agrícola e Agrônomo Doutorando no Programa de Pós Graduação, em Sistemas de Produção Agrícola Familiar da Universidade Federal de Pelotas - RS norbertoan@ibest.com.br

2 - Engenheiro Agrícola Professor Dr. Pesquisador CNPQ Universidade Federal de Pelotas - RS areis@ufpel.edu.br

3 - Arquiteto Professor Dr. Instituto Federal de Educação Sul-Rio-Grandense - RS sandrot@pelotas.ifsul.edu.br

4 - Engenheiro Agrícola Professor Dr. Pesquisador CNPQ Universidade Federal de Pelotas - RS lilles@ufpel.edu.br

5 - Engenheiro Agrícola Professor Dr. Universidade Federal de Pelotas - RS maurof@ufpel.edu.br

426 REVENG

426-432p. ENGENHARIA NA AGRICULTURA, VIÇOSA - MG, V.22 N.5, SETEMBRO / OUTUBRO 2014 


\section{INTRODUÇÃO}

A Agricultura Familiar é, sem dúvida, o segmento de maior importância econômica e social do meio rural. Sabe-se que grande parte da mão de obra rural está ligada à agricultura familiar, sendo responsável pela maioria da produção de alimentos no Brasil.

Conforme Cortez (2010), a agricultura familiar é responsável por cerca de $70 \%$ de todos os alimentos que o brasileiro consome. Embora ocupando apenas um quarto da área, a agricultura familiar responde por $39 \%$ do valor da produção agrícola brasileira.

Em muitos casos, na operação de semeadura, os agricultores de base familiar utilizam animais como meio de tração. $\mathrm{O}$ uso de semeadora tracionada por animais é muito comum em pequenas áreas, principalmente quando a topografia com relação à planimetria e altimetria apresenta configuração bastante irregular.

Andersson et. al. (2009), em trabalho realizado com agricultores de base familiar que foram beneficiados com recursos do PRONAF (Programa Nacional de Fortalecimento da Agricultura Familiar), observaram que esta linha de financiamento foi fator determinante para que estes agricultores adquiram tratores, bem como máquinas agrícolas.

Segundo Corrêa Júnior (2010), utilizando semeadora tracionada por animal, o número de sementes distribuídas em 30 metros de percurso da semeadora foi significativo, ou seja, a velocidade média de deslocamento apresenta influência na operação de trabalho. $\mathrm{O}$ resultado referente ao teor de sementes germinadas após passagem pelo mecanismo dosador de sementes foi significativo, ou seja, foram influenciados pelas velocidades médias de deslocamento da máquina na operação de trabalho, tracionado pelo animal.

As informações disponíveis, tanto com relação à agricultura familiar como com relação às semeadoras, têm caráter subjetivo. Uma forma de tratar esse tipo de informação, de forma objetiva, é por meio da utilização de uma ferramenta conhecida como QFD (Desdobramento da Função Qualidade, do inglês Quality Function Deployment). Segundo Reis e Forcellini (2006), o QFD é uma ferramenta que auxilia a transformação das necessidades dos clientes em características mensuráveis, que ao serem incorporadas no projeto se constituem nos requisitos de qualidade (requisitos de projeto obtidos visando à qualidade). Dentro do desenvolvimento de um produto, os autores situam o emprego da ferramenta na fase inicial do projeto de uma semeadora à tração animal.

Portanto, o objetivo deste trabalho é, por meio da utilização da metodologia de projeto, apoiar os projetistas de máquinas agrícolas com informações que permitam o adequado projeto de semeadoras com tração animal, através da criação de um modelo decisório baseado na Matriz da Casa de Qualidade, listando-se os requisitos de clientes necessários ao desenvolvimento deste produto, chamado de semeadora a tração animal.

\section{MATERIAL E MÉTODOS}

Inicialmente buscaram-se informações, em bibliografia técnica (catálogos de produtos, artigos científicos, teses e dissertações). As informações assim obtidas foram importantes tanto para a identificação de necessidades como para o estabelecimento final das especificações do projeto, fase em que foi necessária a fixação de metas quantitativas e a forma de avaliação das mesmas.

A etapa seguinte consistiu na identificação das necessidades dos clientes. Tendo sido executada com o auxílio de pesquisa bibliográfica, análise de sistemas técnicos similares, consulta a especialistas, simulações de uso e questionário aos clientes. Os clientes neste caso foram identificados como os agricultores familiares que utilizam animais de tração na realização das tarefas dentro da propriedade.

Partiu-se de dados levantados em dois casos estudados separadamente: $\mathrm{O}$ primeiro foi $\mathrm{o}$ desenvolvimento de uma semeadora de tração animal para utilização na agricultura ecológica (TEIXEIRA, 2008) e, o segundo, tratou do desenvolvimento de novas concepções para a dosagem e deposição de precisão para sementes miúdas, de onde, posteriormente, foi selecionada uma lista de necessidades de clientes pertinentes ao desenvolvimento de um dosador de precisão para sementes miúdas, a ser utilizado em uma semeadora voltada a pequenas propriedades rurais (REIS, 2003).

O desdobramento das necessidades dos clientes, através de declarações dos próprios agricultores sobre o projeto, resultou em requisitos dos clientes, tornando estas declarações, de modo a serem facilmente transformadas em linguagem de engenharia, compreensíveis por 
parte dos projetistas. Inicialmente as necessidades levantadas foram distribuídas ao longo do ciclo de vida da semeadora (desde a produção, passando pelo uso, até o descarte) a fim de se identificar mais facilmente se havia alguma coisa repetida, redundante ou ausente. Posteriormente, cada uma das necessidades foi estudada e, quando necessário, decomposta com o intuito de descobrir, em linguagem de engenharia, o que o cliente (agricultores) realmente necessita.

$\mathrm{Na}$ etapa da conversão dos requisitos dos clientes em requisitos do projeto, adotou-se o procedimento empregado por Reis e Forcellini (2006), o qual consiste em; estudar e caracterizar os requisitos dos clientes, confrontarem os requisitos dos clientes com uma classificação de requisitos de projeto e verificar se os requisitos de projeto obtidos apresentam propriedades consideradas desejáveis.

$\mathrm{O}$ estudo dos requisitos dos clientes foi feito estabelecendo-se uma lista de atributos para cada um deles. Atributos estes, que os caracterizam e ajudam na sua compreensão, possibilitando a obtenção de uma lista dos requisitos do projeto.

Os atributos específicos referem-se ao sistema técnico da semeadora, dividindo-se em atributos materiais, energéticos e de controle (REIS; FORCELLINI, 2006). Considerando-se o último nível da classificação proposta por Fonseca (2000), tem-se uma ampla lista de itens para verificação. Por meio da confrontação dos requisitos dos clientes com cada item da lista de classificação apresentada, obtém-se uma lista de requisitos do projeto. A lista obtida é analisada sob a perspectiva das propriedades desejáveis nas especificações de projeto (ROOZENBURG; EEKELS, 1995). Dessa forma, então, obtêm-se os requisitos de projeto que posteriormente são hierarquizados através da matriz da casa da qualidade (QFD).

A primeira tarefa necessária para o uso do QFD é valorar os requisitos dos clientes. A classificação dos requisitos dos clientes em ordem de importância é fundamental na aplicação do QFD. Para isso, foi empregado o diagrama de Mudge, que compara todos os requisitos aos pares (REIS; FORCELLINI, 2006).

Para o uso no QFD, os valores atribuídos aos requisitos dos clientes necessitam ser levados a uma escala de mais fácil compreensão, então, aplicou-se uma análise de frequência com cinco intervalos de valores, de um a cinco.

Uma das atividades mais importantes no QFD é estabelecer o grau de relacionamento entre os requisitos dos clientes (o quê?) e os requisitos do projeto (como?). A identificação de um relacionamento e do seu grau será facilitada para a equipe de projeto se o seguinte procedimento for formalizado: (a) iniciando pelo primeiro como, fazer as perguntas - pode esse "como" influenciar esse "o quê"? Esse "o quê" afeta esse "como"? (b) se a equipe responder com um sim a uma das perguntas anteriores, perguntar - a relação é fraca, média ou forte? (c) passar a análise do próximo $o$ quê repetindo-se o procedimento anterior, ao chegar-se no último item, passa-se para o próximo como (REIS; FORCELLINI, 2006).

Para o estabelecimento das especificações de projeto aos requisitos de projeto obtidos e hierarquizados nas etapas anteriores (que representam qualitativamente os objetivos do projeto), necessitam-se atribuir-se metas quantitativas a serem atingidas. Assim, as especificações de projeto de uma semeadora de tração animal para a agricultura familiar foram concluídas, atribuindo-se um valor meta para cada requisito de projeto considerado.

\section{RESULTADOS E DISCUSSÃO}

Reis et. al. (2002) apresentam uma proposta para implementação computacional dessa comparação, assim como uma descrição detalhada dessa ferramenta. Durante a aplicação do diagrama de Mudge, a decisão sobre qual requisito do par é o mais importante e em que medida, tem por base o conhecimento adquirido dos clientes do projeto através dos questionários aplicados. Nos casos em que os requisitos não constam no questionário, a valoração tem por base o conhecimento adquirido pela própria equipe ao longo do processo de projeto.

A partir da análise dos dados levantados por Teixeira (2008) e Reis (2003), referente aos requisitos de clientes para uma semeadora de tração animal e um dosador de precisão para sementes miúdas, respectivamente, foram selecionados 15 requisitos, distribuídos nas fases de vida do produto (semeadora para tração animal) a fim de verificaremse possíveis redundâncias, conforme Quadro 1.

A caracterização dos requisitos dos clientes permitiu que eles fossem confrontados, individualmente, com a classificação dos requisitos de projeto estabelecida por Fonseca (2000). A utilização desta última classificação serviu de lista de verificação, o que facilitou a conversão dos 
requisitos dos clientes em requisitos de projeto, auxiliando também na geração de uma lista ampla, na qual se procurou a inclusão de requisitos pertinentes em todos os níveis considerados na classificação.

Como resultados dessa comparação foram relacionados 16 requisitos de projeto. Embora os requisitos obtidos possam estar completos (inclusão de objetivos englobando todos os aspectos do problema), eles foram analisados, conforme o proposto, à luz dos critérios de Roozenburg e Eekels (1995), para que a lista final tenha as características desejáveis numa especificação de projeto.

Foram identificadas 15 declarações de necessidades de clientes, as quais foram transformadas em 16 requisitos clientes, os quais, por sua vez, resultaram em 14 requisitos de projeto hierarquizados e distribuídos ao longo de todo o ciclo de vida do produto, resultando nas especificações para o projeto de um mecanismo dosador de sementes de milho e feijão.

Nessa análise foram identificados alguns requisitos de projeto com características indesejáveis, e outros que podem ser considerados como premissas do projeto do produto, motivo pelo qual foram excluídos, resultando numa lista de 14 requisitos.
A hierarquização dos requisitos de projeto foi executada por meio da aplicação do Diagrama de Mudge, que resultou na valoração desses requisitos na seguinte ordem decrescente: ter baixo custo $(16,7 \%)$, ter precisão na dosagem das sementes $(13,4 \%)$, ser precisa na distribuição das sementes $(13,0 \%)$, serem fácil de fabricar $(12,6 \%)$, ter pequena danificação das sementes $(8,5 \%)$, terem funcionamento independente do nível de sementes no reservatório $(6,1 \%)$, ser de simples operação $(5,7 \%)$, ter número de regulagens adequadas $(5,7 \%)$, ser durável $(5,3 \%)$, ter manutenção de fácil execução $(3,3 \%)$, ter manutenção de custo reduzido $(2,8 \%)$, ser fácil de regular $(2,8 \%)$, ter montagem do dosador sem o auxílio de ferramentas $(1,6 \%)$, ter boa resistência mecânica $(1,2 \%)$, ter manutenção de baixa frequência $(0,8 \%)$, oferecer segurança ao operador $(0,4 \%)$.

Na Figura 1 é mostrada a matriz da casa da qualidade, onde se observa os relacionamentos entre os requisitos dos clientes e os requisitos de projeto, a correlação entre os requisitos de projeto e a hierarquização dos requisitos de projeto obtida levou em consideração apenas a matriz de relacionamentos.

Quadro 1. Síntese dos requisitos de clientes separados por fases do ciclo de vida do produto

\begin{tabular}{|l|l|}
\hline \multicolumn{1}{|c|}{ Fase } & \multicolumn{1}{c|}{ Requisitos de Clientes } \\
\hline Projeto & (não identificado) \\
\hline Fabricação & Ser fácil de fabricar \\
\hline \multirow{2}{*}{ Comercialização } & Ter baixo custo \\
& Ser durável \\
\hline \multirow{3}{*}{ Utilização } & Ter número de regulagens adequado \\
& Ser fácil de regular \\
& Ser de simples operação \\
& Ter montagem do dosador sem o auxílio de ferramentas \\
& Ter precisão na dosagem \\
& Ser precisa na distribuição de sementes \\
& Ter pequena danificação de sementes \\
& Ter funcionamento independente do nível de sementes \\
& Ter boa resistência mecânica \\
& Ter manutenção de fácil execução \\
& Ter manutenção de baixa freqüência \\
& Ter manutenção de custo reduzido \\
\hline \multirow{2}{*}{ Manutenção } &
\end{tabular}




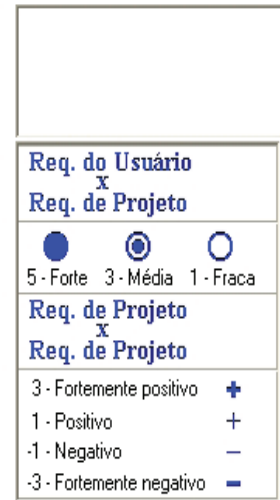

\begin{tabular}{|l|}
\hline Requisitos do usuário \\
\hline Ser fácil de fabricar \\
\hline Ter baixo custo \\
\hline Ser durável \\
\hline Ter número de regulagens. \\
\hline Ser fácil de regular \\
\hline Ser de simples operaçäo \\
\hline Ter montagem do dosador \\
\hline Ter precisäo na dosagem \\
\hline Ser precisa na distribuçäo \\
\hline Ter pequzuna danificaçäo d \\
\hline Ter funcionamento indeper \\
\hline Ter boa resistência mecâni \\
\hline Ter manutençäo de fácil ex \\
\hline Ter manutençäo de baixa f \\
\hline Ter manutençäo de custo rn \\
\hline
\end{tabular}
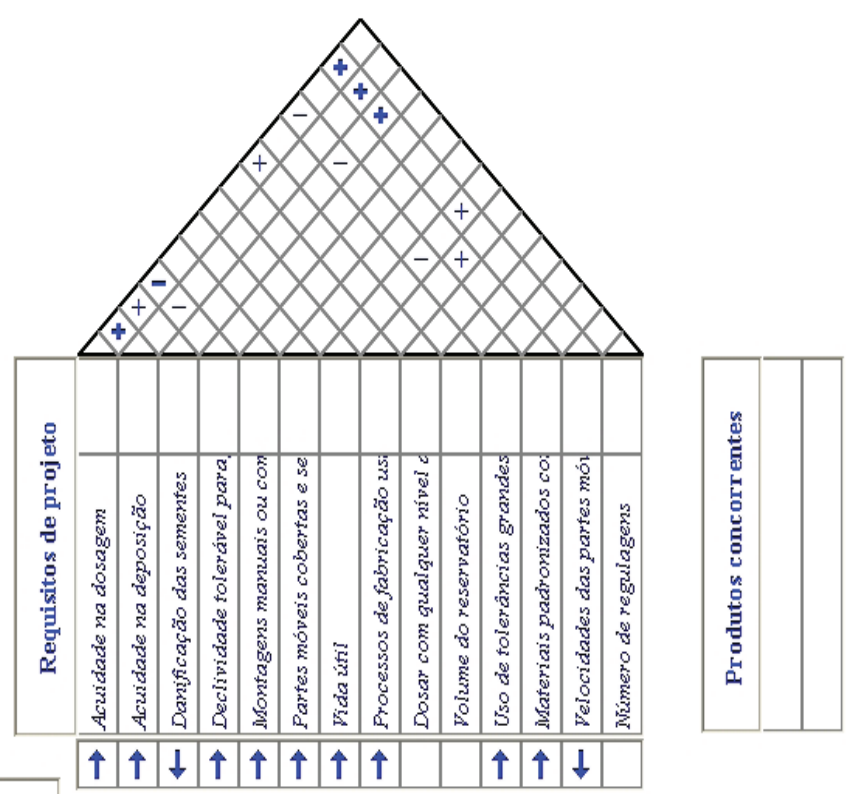

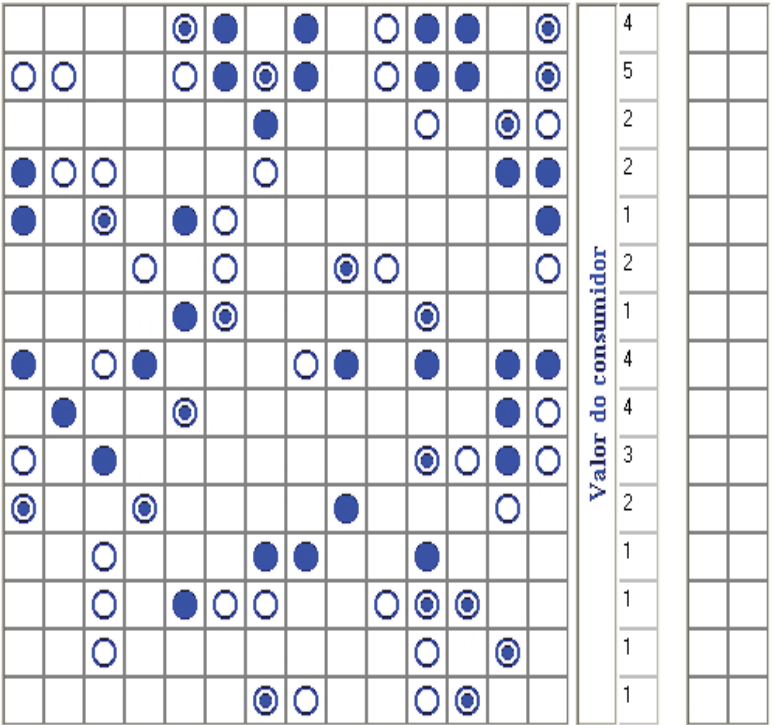

\begin{tabular}{|l|l|}
\hline \multicolumn{2}{|c|}{ Classificação sem a concorrência } \\
\hline Valor da matriz principal \\
\hline Critério sem telhado \\
\hline Valor com o telhado \\
\hline Critério com telhado \\
\hline
\end{tabular}

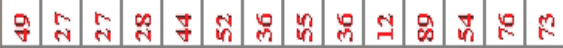

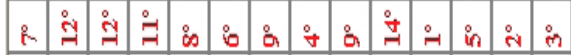

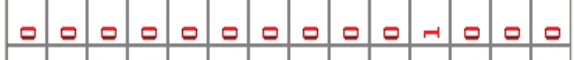

\begin{tabular}{|c|c|c|c|c|c|c|c|c|c|c|c|c|c|c|}
\hline Classificação com a concorrência & & & & & & & & & & & & & & \\
\hline Valor da matriz principal & $\square$ & 口 & $\square$ & $\square$ & $\square$ & $\square$ & 口 & $\square$ & 口 & $\square$ & $\square$ & $\square$ & 口 & 口 \\
\hline Critério sem telhado & $\stackrel{-1}{-1}$ & $\therefore$ & $\stackrel{-1}{-1}$ & $\stackrel{-1}{-1}$ & $\stackrel{-1}{-1}-100$ & $\stackrel{1}{-1}$ & $\therefore$ & $\therefore$ & $\therefore$ & $\stackrel{-1}{i}$ & $\therefore$ & $\stackrel{-}{-1}$ & $\therefore$ & $\stackrel{-1}{-1}$ \\
\hline Valor com o telhado & $\square$ & $\square$ & a & $\square$ & a & $\square$ & a & $\square$ & $\square$ & a & $\square$ & $\square$ & $\square$ & $\square$ \\
\hline Critério com telhado & 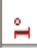 & $\therefore$ & 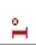 & $\stackrel{-1}{\sim}$ & $\therefore$ & 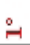 & $\stackrel{-1}{-1}$ & $\therefore$ & $\therefore$ & $\stackrel{-}{-}$ & 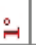 & 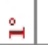 & $\stackrel{-1}{1}$ & $\stackrel{-1}{-1}$ \\
\hline
\end{tabular}

Figura 1. Matriz da casa da qualidade do dosador de precisão para sementes de milho e feijão com dupla saída.

\section{REVENG}


A atribuição de valores meta às especificações de projeto ordenadas pelo QFD resultou em especificações do projeto, mostradas de acordo com a sua importância, no Quadro 2.

$\mathrm{O}$ fato dos requisitos dos clientes relacionados com o processo de produção terem sido apontados como os mais importantes (três dentre os cinco constantes no terço superior da hierarquização), ressalta a importância da redução de custos de fabricação e, consequentemente, a redução do custo de comercialização a ser atingido pelo produto, os quais tem grande significância no desenvolvimento de equipamentos destinados a agricultura familiar (Quadro 2).

O terço intermediário demonstra que os aspectos de funcionamento, segurança e obsolescência deverão ser atendidos na busca de equipamentos modernos para utilização nas pequenas propriedades quando da sua escolha ou uso. Aspectos operacionais simples como a montagem manual das partes (rapidez e simplicidade) e acuidade na dosagem evidenciam, também, o alto grau de otimização de desempenho aliado à praticidade que vem sendo buscada na agricultura brasileira. Essa análise permite inferir que os equipamentos de semeadura desejados na agricultura brasileira devem ter, além do desempenho funcional satisfatório, a um custo reduzido, um projeto voltado para a facilidade de operação e de manutenção.

Como consequência, foi possível verificar que o ganho de conhecimento, a respeito do problema de trabalho experimentado ao longo da fase de projeto informacional, é um resultado positivo na aplicação da metodologia utilizada. As etapas ordenadas sistematicamente do projeto informacional e os métodos e ferramentas empregados proporcionam um entendimento crescente da complexidade do problema em questão.

Quadro 2. Especificações de projeto para dosador de precisão para sementes de milho e feijão com dupla saída

\begin{tabular}{|c|c|c|c|}
\hline $\mathrm{N}^{\mathrm{o}}$ & Especificações de projeto & Unidade & Objetivo \\
\hline 1 & Uso de tolerâncias grandes & $\begin{array}{c}\text { Classe IT } 8 \\
\text { ou IT } 9 .\end{array}$ & $\begin{array}{l}\text { Classe de tolerância conforme NBR } \\
6158 \text {, compatível com processos } \\
\text { usuais de fabricação }\end{array}$ \\
\hline 2 & Velocidades das partes móveis & $\mathrm{m} \cdot \mathrm{s}^{-1}$ & $<0,3 \mathrm{~m} \cdot \mathrm{s}^{-1}$ \\
\hline 3 & Número de regulagens & $\mathrm{N}^{\mathrm{o}}$ & $>3$ \\
\hline 4 & Processos de fabricação usuais & $\%$ proc. & $>80 \%$ \\
\hline 5 & Materiais padronizados comuns & $\%$ & $>80 \%$ \\
\hline 6 & $\begin{array}{l}\text { Partes móveis cobertas e sem } \\
\text { cantos vivos }\end{array}$ & $\%$ & $100 \%$ \\
\hline 7 & Acuidade na dosagem & $\begin{array}{l}\text { Espaçamentos } \\
\text { aceitáveis }\end{array}$ & $>60 \%$ \\
\hline 8 & $\begin{array}{l}\text { Montagens manuais ou com } \\
\text { auxilio de poucas ferramentas }\end{array}$ & $\mathrm{N}^{\mathrm{o}}$ ferramentas. & No máximo duas \\
\hline 9 & Vida útil & Anos & 5 anos \\
\hline 10 & $\begin{array}{c}\text { Dosar com qualquer nível de } \\
\text { sementes no reservatório }\end{array}$ & $\%$ & $\begin{array}{l}\text { Maior que } 1 \% \text { da capacidade do } \\
\text { reservatório }\end{array}$ \\
\hline 11 & $\begin{array}{l}\text { Declividade tolerável para } \\
\text { funcionamento }\end{array}$ & Graus & $\geq 11^{\circ}$ \\
\hline 12 & Acuidade na deposição & $\begin{array}{c}\text { Espaçamentos } \\
\text { aceitáveis }\end{array}$ & $>60 \%$ \\
\hline 13 & Danificação das sementes & $\%$ & $<2 \%$ \\
\hline 14 & Volume do reservatório & Litro & Ainda não fixado \\
\hline
\end{tabular}


Nesse ponto, contribuíram significativamente para a identificação das necessidades dos clientes, a transformação delas em requisitos dos clientes e destes em requisitos do projeto e a posterior hierarquização através da primeira matriz do QFD. A identificação das necessidades dos clientes através do ciclo de vida do produto permitiu que se chegasse a informações importantes ao desenvolvimento do projeto. O tratamento dessas informações, ou seja, os vários passos empregados para que as necessidades dos clientes fossem transformadas em requisitos de projeto, ajudaram sobremaneira no entendimento de todos os aspectos envolvidos no projeto do dosador de precisão para sementes miúdas, a ser colocado nesta semeadora à tração animal.

\section{CONCLUSÕES}

- O emprego da metodologia de projeto apresentada propiciou um ganho apreciável de conhecimento a respeito do problema de projeto durante a fase de projeto informacional;

- Dentre os cinco requisitos de projeto mais importantes, apenas dois não estão relacionados com aspectos construtivos do produto (velocidade das partes móveis, número de regulagens);

- Os cinco requisitos apontados como mais importantes são por ordem: uso de tolerâncias grandes, velocidades das partes móveis, número de regulagens, processos de fabricação usuais, materiais padronizados comuns.

\section{REFERÊNCIAS BIBLIOGRÁFICAS}

ASSOCIAÇÃO BRASILEIRA DE NORMAS TÉCNICAS (ABNT). NBR 6158 Sistema de tolerâncias e ajustes. Rio de Janeiro, 1995. 11p.

ANDERSSON, N.L.M. MACHADO, A.L.T. REIS, A.V. MACHADO, R.L.T. MEDEIROS, F.A. TROGER, H.C.H. TEIXEIRA, S.S. MORAIS, C.S. Características das unidades familiares de produção que adquiriram tratores, através do PRONAF, na região da Santa Áurea - Pelotas/RS. In: ENCONTRO DA PÓS-GRADUAÇÃO, 11. 2009, Pelotas. Anais...Pelotas: UFPel, 2009. 1 CD.
CORRÊA JÚNIOR, D., GARCIA, R.F., VALE, W.,G.; BIAZATTI, M. A., VASCONCELLOS JUNIOR, J.F. Influência da velocidade de deslocamento no desempenho de uma semeadoraadubadora de tração animal no norte fluminense. Apresentado no II Congresso Fluminense de Iniciação Científica e Tecnológica. Anais (2010).

CORTEZ, G; Disponível em <http://www.com/.../ agricultura-familiar-faz-uma-revolucaono-campo-e-garante-inflaca-baixa-dosalimentos $>$ Acesso em: 11/11/2010.

FONSECA, A.J.H. Sistematização do processo de obtenção das especificações de projeto de produtos industriais e sua implementação computacional. 2000. 180f. Tese (Doutorado em Engenharia Mecânica) - CTC/EMC, Universidade Federal de Santa Catarina, Florianópolis.

REIS, A.V. Desenvolvimento de concepções para dosagem e deposição de precisão para sementes miúdas. 2003. 277p. Tese (Doutorado em Engenharia Mecânica) - Centro Tecnológico, Universidade Federal de Santa Catarina, Florianópolis, 2003.

REIS, A.V.; FORCELLINI, F.A. Obtenção de especificações para o projeto de um mecanismo dosador de precisão para sementes miúdas. Revista Engenharia rural. v.17., n.1, julho/2006.

ROOZENBURG, N.F.M.; EEKELS, J. Product design: fundamentals and methods. Chichester: John Wiley \& Sons, 1995. 408p.

TEIXEIRA, S.S. Projeto conceitual de uma semeadora de milho e feijão voltada para a agricultura familiar de base ecológica. 2008. 113p. Dissertação (Mestrado em Mecanização Agrícola). Programa de Pós-Graduação em Sistemas de Produção Agrícola Familiar.

TEIXEIRA, S.S.; REIS, A.V. Distribuição longitudinal de sementes de milho com dosador de disco horizontal operando com uma ou duas saídas de sementes. Revista Ciência Rural, Santa Maria, v.39, n.8, p.2417-2421, nov, 2009. 